\title{
Efficacy of different selective media for the isolation of salmonellae from faeces
}

\author{
J. ZAJC-SATLER AND S. BANIČ \\ From the Institute of Microbiology, Medical Faculty, Ljubljana, Yugoslavia
}

SYNOPSIS Comparative results obtained in isolating salmonellae from faeces by the use of tetrathionate broth, MS, and MM enrichment medium are given. The best results were obtained by $\vec{\infty}$ tetrathionate broth prepared from infusion broth. The MS as well as the MM medium increased the $\sigma_{0}$ total number of positive results.

There are many efficient selective media for the isolation of salmonellae, but none of them is as efficient as desired. To obtain the best results many authors recommend the use of two or three different enrichment media in addition to the direct plates (Sen, 1964; Guinée and Kampelmacher, 1962; Taylor, Buttiaux, and Catsaras, 1963). The purpose of this study was to compare the efficacy of the MM (Rappaport, Konforti, and Navon, 1956) and MS (Banič, 1963) media with that of the MüllerKauffmann enrichment medium and of direct plating for the isolation of salmonellae from faeces.

\section{MATERIALS AND METHODS}

MEDIA The Wilson-Blair agar and SS agar were prepared according to Priručnik mikrobiolcških metoda (Manual of Microbiological Methods, 1953), tetrathionate broth according to the formula given by Kauffmann (1941), and the MM medium according to the formula given by Rappaport et al. (1956).

The MS medium, which is composed of nutrient broth Difco $+0.2 \%$ yeast extract Difco $+0.05 \%$ sodium hydrogen selenite $\left(\mathrm{NaHSeO}_{3}\right)$ (Merck) $+3.4 \% \mathrm{MgCl}_{2}$, was prepared as described in a previous paper (Banič, 1963). It should be mentioned that the stock solution of $40 \% \mathrm{MgCl}_{2}$ used in the preparation of the $\mathrm{MM}$ medium was made up according to the method of Rappaport et al. (1956) so that $100 \mathrm{~g}$. of $\mathrm{MgCl}_{2}$ (the whole content of a newly-opened bottle) was dissolved in $250 \mathrm{ml}$. of distilled water, whereas the stock solution of $40 \% \mathrm{MgCl}_{2}$ for the MS medium was prepared by placing $100 \mathrm{~g}$. of $\mathrm{MgCl}_{2}$ (the whole content of a newly-opened bottle) in a sterile measured cylinder and then distilled water was added to make the solution up to $250 \mathrm{ml}$.

Altogether, 1,090 specimens of faeces were examined. Each specimen was first seeded on a direct Wilson-Blair and SS agar plate. Then about $1 \mathrm{~g}$. of the faeces was emulsified in $10 \mathrm{ml}$. of distilled water, and four drops of this suspension were dropped into a tube of each of the

Received for publication 14 July 1965. enrichment media. After incubation for 18 hours aloopful of each of the enrichment media was plated on to $Z$ Wilson-Blair and SS agar. The plates were incubated? overnight and then examined for salmonellae together with the direct plates according to the standard methods.

RESULTS

Two hundred Salmonella strains were isolated. Among them the following Salmonella species were identified: 65 strains of $S$. paratyphi $\mathrm{B}$, six strains of $S$. java, 47 strains of $S$. typhimurium, 24 strains of $S$. brandenburg, 16 strains of $S$. derby, nine strainsō of $S$. oranienburg, eight strains of $S$. enteritidis, six strains of $S$. blockley, five strains of $S$. heidelberg, four strains of $S$. typhi, three strains of $S$. tennessee, three strains of $S$. onatam, two strains of $S$. thompson one strain of $S$. livingstone, and one strain of S. newport.

The efficacy of each of the selective media usedo in the study is shown in Tables I-III.

\section{DISCUSSION}

From Table I it can be seen that the direct Wilson- $\rightarrow$ Blair plate showed 91 Salmonella strains, $45.5 \%$ of․ㅡ. all the strains isolated. The direct SS agar platon showed $39(19.5 \%)$ strains; the Müller-Kauffmann enrichment medium $183(90.5 \%)$ strains; the MSO enrichment medium 172 strains $(86 \%)$; the MMN enrichment medium 162 strains $(81 \%)$.

As Table III shows, subculturing on Wilson-Blair agar was much more efficient that on SS agar. Hence the use of Wilson-Blair agar for subculturing from? enrichment media seems strongly indicated. Theo additional use of SS agar for subculturing is, how ever, useful, because some strains were isolated on the SS agar but not on the Wilson-Blair agar.

In our hands the Müller-Kauffmann medium was్ 
TABLE I

COMPARATIVE EFFICACY OF VARIOUS

SELECTIVE MEDIA FOR THE ISOLATION OF SALMONELLA SPECIES

Medium
No. of Salmonella
Strains Isolated

$\begin{array}{lr}\text { Wilson-Blair (direct plate) } & 91 \\ \text { SS agar (direct plate) } & 39 \\ \text { Tetrathionate broth } & 183 \\ \text { MM } & 172 \\ \text { MS } & 162\end{array}$

TABLE I I

NUMBER OF SALMONELLA STRAINS ISOLATED ON ONLY ONE OF THE FIVE SELECTIVE MEDIA OR ONLY ON THE MM AND MS MEDIA TOGETHER Medium No. of Salmonella Strains Isolated

\begin{tabular}{ll}
\hline Wilson-Blair (direct plate) & 2 \\
SS agar (direct plate) & 0 \\
Tetrathionate broth & 9 \\
MM & 3 \\
MS & 2 \\
MM + MS & 4
\end{tabular}

TABLE III

COMPARATIVE EFFICACY OF THE WILSON-BLAIR MEDIUM AND SS AGAR FOR SUBCULTURING FROM THE ENRICHMENT MEDIA

$\left.\begin{array}{lll}\text { Enrichment Medium } & \text { Subculture on Agar } & \begin{array}{l}\text { No. of Salmonella } \\ \text { Strains Isolated }\end{array} \\ \hline \text { Müller-Kauffmann } & \text { Wilson-Blair } & 181 \\ & \text { SS } & 130 \\ \text { MS } & \text { Wilson-Blair } & 169 \\ & \text { SS } & 103 \\ \text { MM } & \text { Wilson-Blair } & 162 \\ & \text { SS } & 86\end{array}\right\} 162$

the most efficient of all media for isolating salmonellae from faeces, although with the MS and MM enrichment media fairly good results were also obtained. When the MS and MM media are compared, in our material the MS medium gave somewhat better results (Tables I and III).

It is interesting that Rappaport et al. (1956) observed a greatly increased recovery rate of salmonellae from faeces with the MM medium compared with the Müller-Kauffmann medium. Similarly, Iveson, Kovacs, and Laurie (1964) obtained significantly better results in isolating salmonellae from contaminated desiccated coconut with Rappaport enrichment medium than with tetrathionate broth. These differing results pose the question of the cause of this discrepancy. In our opinion it might be the fact that in our laboratory the tetrathionate broth is prepared from infusion broth, whereas Iveson et al. (1964) used a dehydrated tetrathionate broth (Difco), as did Rappaport et al. (1956) who used a dehydrated nutrient broth (Difco). According to our experience freshly prepared media from infusion broth usually support the growth of bacteria better than do dehydrated media. It is possible that the Müller-Kauffmann medium is much more efficient when prepared from infusion broth than using a dehydrated medium. It would be well worth examining this possibility.

The MS and MM media are undoubtedly efficient enrichment media. In our laboratory the MS medium gave somewhat better results, but the differences are statistically insignificant. Which of them should be used mainly depends on which medium can be more easily prepared in a given laboratory.

As a rule the MS and MM media should be used only in addition to the standard Müller-Kauffmann medium with a view to increasing the number of positive results. In our material (Table II) the MS and MM media did not greatly increase the number of positive isolations, but in another laboratory if a dehydrated tetrathionate broth were used, the increase of positive results using either the MS or the MM medium might be significant.

We wish to thank Mrs. I. Mamilovič, Miss P. Ferbežar, and Mrs. D. Zavodnik for technical assistance.

\section{REFERENCES}

Banič, S. (1963). J. Hyg. (Lond.), 62, 25.

Guinée, P. A. M., and Kampelmacher, E. H. (1962). Antonie v. Leeuwenhoek, $28,417$.

Iveson, J. B., Kovacs, N., and Laurie, W. (1964). J. clin. Path., 17, 75.

Kauffmann, F. (1941). Die Bakteriologie der Salmonella-Gruppe. Munksgaard, Copenhagen.

Priručnik mikrobioloskih metoda (Manual of Microbiological Methods). (1953). Belgradex-Zagreb.

Rappaport, F., Konforti, N., and Navon, B. (1956). J. clin. Path., 9, 261.

Sen, R. (1964). Indian J. Path. Bact., 7, 93.

Taylor, W. I., Buttiaux, R., and Catsaras, M. (1963). Ann. Inst. Pasteur., 104, 638. 